\title{
Effect of Omega-3 Supplementation on Hormone Profile in Women with Poly Cystic Ovarian Syndrome
}

\author{
Mamta Pareek $^{1}$ and Reshma Boolchandani ${ }^{2}$ \\ ${ }^{1}$ Research Scholar, Department of Home Science, \\ University of Rajasthan, Jaipur. \\ ${ }^{2}$ Associate Professor, Department of Home Science, \\ University of Rajasthan, Jaipur.
}

\begin{abstract}
Poly Cystic Ovarian Syndrome (PCOS) affects women in their reproductive ages, and is a hormonal disorder usually marked by high levels of androgen hormones. Approximately 2.2-26 percent of Indian women suffer from PCOS. Dietary modifications and exercise normalize the androgen levels and thus improve reproduction, hence are effective treatments for PCOS management. Omega-3 Fatty acid supplementation (i.e. fish oil capsule) are important in the management of PCOS. The present study aimed at assessing the impact of fish oil capsule supplementation on serum LH, FSH and Testosterone levels of women with PCOS. For the present study, forty women between the ages of 18-40 years, having PCOS were selected using purposive sampling technique. Blood samples were taken and analysed for the parameters to be studied, before and after 3 months of supplementation. BMI of the respondents was also assessed prior to and after intervention. The results of the study reveal a significant decrease (at $0.01 \%$ ) in the mean serum LH levels. A statistically non-significant reduction in the mean Testosterone and mean FSH levels of the respondents was observed. Supplementing the two Fish Oil capsules per day for a period of 90 days resulted in an improved serum LH level.
\end{abstract}

Key words: PCOS, Hormone profile, LH, FSH, Testosterone, Omega -3 Fatty Acids, fish oil

\section{Introduction:}

Poly Cystic Ovarian Syndrome (PCOS), was first reported in 1935 by Stein and Leventhal, and is now prevalent as the commonest female endocrine disorder (Baptiste et al, 2010) causing anovulatory infertility, affecting up to $15 \%$ of women in the US and up to 33\% in UK (Fakhoury et al. 2012, Taher et al, 2012, Ganie and Karla, 2011). Around 2.2\% to $26 \%$ of the Indian women have been reported to have this disorder ( Nidhi et al., 2011). The causes implicated for PCOS are multifactorial. Raised levels of androgens \& insulin, chronic inflammation, genetic \& environmental factors as well as obesity, contribute to the pathogenesis of this disorder (Kelly et al 2013; Goodarzi et al 2011; Diamanti et al 2009 and Arslanian \& Witchel, 2002). Idiopathic hirsutism and oligomenorrhea are commonly reported in women with polycystic ovaries (Adamas et al 1986). These are accompanied by other symptoms which include irregular menstruation, acne (Alemzadeh et al 2010; Hassa et al 2006) alopecia, miscarriage (Eid et al., 2005) and obesity which is an important contributing factor for PCOS (Setji et al 2007). Research shows that $35-50 \%$ of women with multiple ovarian cysts are obese. A high rate of hirsuitism and anovulation is observed in obese women as compared to non-obese women with ovarian cysts (Pettigrew et al., 1997). Metabolic syndrome in US women with PCOS is commonly reported by $33 \%-50 \%$ of women, as compared to $12 \%$ in a similarly aged general population (Glueck et al, 2003). Becoming pregnant may be difficult for women with ovarian cysts as they have high levels of serum testosterone. These high testosterone levels may bring about the symptomatology of PCOS and also affect organs like brain, liver, pancreas, muscle and fat ( $\mathrm{NIH}$, 2012) Apart from the raised serum androgens, PCOS induced other endocrine abnormalities may be increased levels of Luteinizing Hormone (LH), altered levels of FSH, raised $\mathrm{LH} / \mathrm{FSH}$ ratios and hyperinsulinemia. An increased risk of NIDDM, gestational diabetes, stroke, raised blood lipid 
levels, coronary artery disease and endometrial carcinoma are associated with PCOS (Eid et al 2005).

Dietary modifications and exercise improves the androgen levels, reproductive function, hence are effective treatments for the management of PCOS (Moran et al. 2004). Research shows that a 5-10\% loss in body weight in overweight PCOS women by restriction of energy, reduces hyperinsulinemia, lowers the raised androgen levels (Hoeger et al., 2006), brings about menstrual cycle regularity (Crosignani et al., 2003), and decreases the risk of heart diseases (Moran et al., 2003). Along with weight loss, achieving the desirable levels of circulating insulin concentrations exerts many benefits (Norman et al., 2002). Supplementation of the diet with Omega-3 Fatty acids is important in the management of PCOS.

Fish oil exerts antiatherogenic and antiinflammatory effects. Dietary Polyunsaturated Fatty Acids (PUFA) also have been proven to have a beneficial effect on glycemic and lipidemic profile (Ebbesson et al 2005). Eicosapentaenoic Acid (EPA) and Docosahexaenoic Acid (DHA) alter metabolic parameters positively $\&$ this can be due to the increase in adiponectin production (Kartz et al 2008). Mehendale et al (2009) reported reduced EPA (plasma) and erythrocyte DHA levels in infertile women with the control group and postulated that omega-3 fatty acids help in managing the female infertility. Cussons et al (2009) reported that there was a beneficial effect of omega-3 fatty acid supplementation on cardiometabolic risk factors in PCOS patients.

\section{Objective}

The objective behind conducting the present study was to study the impact of fish oil capsules on Leutinising Hormone (LH), Follicle Stimulating Hormone (FSH) and Testosterone levels of women with PCOS.

\section{Materials and Methods}

For the present study, forty women with polycyctic ovarian syndrome, were selected using purposive sampling technique from a hospital in Jaipur, India. The selection of the respondents was done as per the inclusion criteria. They were given 2 capsules of fish oil per day (each containing $300 \mathrm{mg}$ fish oil) for an intervention period of 90 days. Blood samples were analysed for the parameters under study, at baseline and after 90 days of supplementation.

3.1 Inclusion Criteria: Women who fulfilled the following inclusion criteria were selected for the study: increased androgen levels (testosterone levels / facial hirsutism), irregular menstrual cycle, ultrasound confirming the presence of PCOS, willing to be a part of the study, and residing in Jaipur city.

3.2 Intervention and Assessments: The respondents were provided with 2 fish oil capsules per day (each containing $300 \mathrm{mg}$ fish oil) for an intervention period of 90 days. At a time, capsules were provided for 15 days after which the researcher repeated the distribution. They were asked to consume the capsules as per the directions. The parameters studied at pre and post intervention were serum LH, FSH, Testosterone levels and Body Mass Index (BMI). Blood samples were analysed using Auto analyser and were withdrawn between the first day and fifth day of the menstrual cycle.

\section{Results}

The mean age of the respondents was $19.5 \pm 2.83$ years. It was observed that most of the respondents who had PCOS were aged between 15-30 years.

The present study reveals a statistically significant reduction $(\mathrm{p}<0.01)$ in the mean $\mathrm{LH}$ levels after supplementation of the diet with omega 3 fatty acids. The mean FSH levels of the respondents reduced non-significantly from pre to post intervention (Table 4.1; Figure 4.1). The serum testosterone levels of the subjects also reduced nonsignificantly (Table 4.1; Figure 4.2).

Table 4.1: Mean Difference (from pre to post intervention) in Hormone Profile and Body Mass Index of subject on fish oil capsule supplementation

\begin{tabular}{|c|c|c|}
\hline S.No & Variable & $\begin{array}{c}\text { Mean Difference } \\
\text { (From pre to post } \\
\text { intervention) }\end{array}$ \\
\hline 1 & $\begin{array}{c}\text { Testosterone } \\
(\mathrm{ngm} / \mathrm{dl})\end{array}$ & $\downarrow 3.52 \mathrm{~ns}$ \\
\hline 2 & $\mathrm{LH}(\mathrm{mIU} / \mathrm{ml})$ & $\downarrow 1.96^{* *}$ \\
\hline 3 & $\mathrm{FSH}(\mathrm{mIU} / \mathrm{ml})$ & $\downarrow 0.15 \mathrm{~ns}$ \\
\hline 4 & Weight $(\mathrm{kg})$ & $\downarrow 0.18 \mathrm{~ns}$ \\
\hline 5 & BMI & $\downarrow 0.06 \mathrm{~ns}$ \\
\hline \multicolumn{2}{|c|}{$\mathrm{NS}=$ Non-significant; ** $\mathrm{p}<0.01$} \\
\hline
\end{tabular}




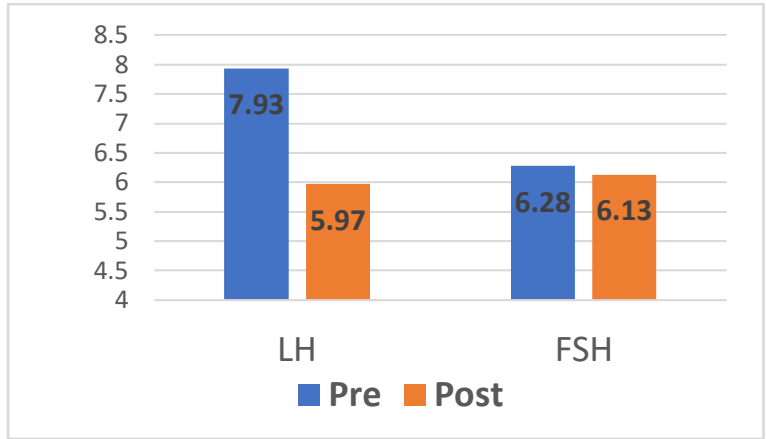

Figure 4.1: Mean LH and FSH levels of the respondents at Pre and Post Intervention

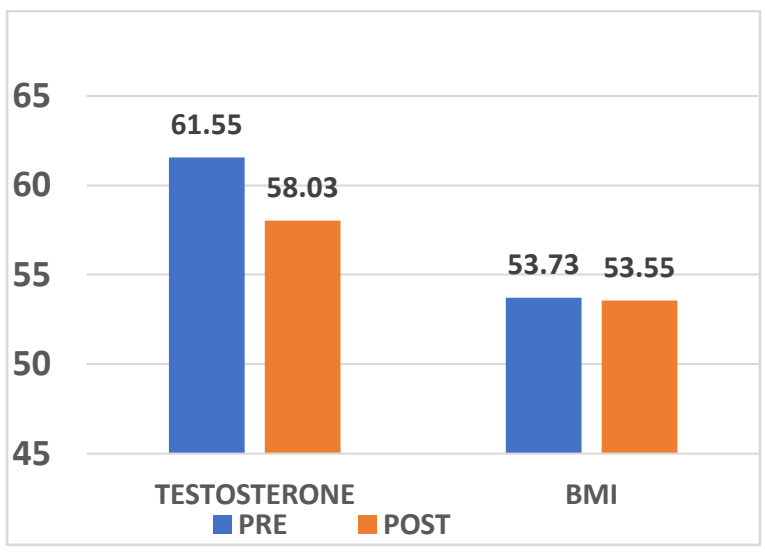

Figure 4.2: Mean Testosterone levels and BMI of respondents at Pre and Post Intervention

A statistically non-significant reduction was observed in the difference of mean values (the difference in the values of means from pre intervention to post intervention) of Body Mass Index (BMI) of the subjects (Table 4.1; Figure 4.2)

\section{Discussion}

Research indicates that PCOS has started affecting younger girls nowadays, thus bringing about a need to generate awareness about PCOS among young females (Bronstein et al., 2011).

PCOS is a common condition (Kauffman et al, 2008; Azziz et al, 2004) which makes a woman more prone to problems related to reproduction like infertility, cancer of the endometrium, delayed menopause (Navaratnarajah et al, 2008; Balen et al, 1995). They also have elevated chances of metabolic alterations, like insulin resistance, adult onset diabetes, elevated lipid levels and diseases of the heart (Christakou et al, 2008; Talbott et al, 2004). Ovulation is enhanced by increased levels of omega-3 fatty acids which are alpha-linolenic, EPA and DHA. Supplementing the diet with omega 3 fatty acids and consuming food sources rich in these fatty acids may be beneficial in glucose clearance, insulin sensitivity, reducing fat deposition, promoting heart health, promoting ovulation \& correcting depression (Brannon,2005) and also in improving the hormone profile by altering the LH levels \& thereby decreasing the testosterone concentration (Forouhia et al, 2015; Nadjarzadeh et al, 2013). LH helps in androgen production by theca cells, whereas aromatization of these androgens to oestradiol by granulosa cells is done by FSH (Bart et al, 1997).

The findings of the present study show a significant reduction in the mean levels of Luteinizing Hormone after fish oil capsule supplementation and this may prove beneficial for the treatment of PCOS. A similar study reported a decline in the serum LH as well as testosterone levels and simultaneously, a significant increase in sex hormone binding globulin after supplementation with omega 3 fatty acids over a period of 6 months (Oner and Muderris et al 2013).

In a meta-analysis it was concluded that Omega-3 supplements containing EPA and DHA were of help in achieving statistically significant reductions in testosterone levels of PCOS women (Forouhia et al, 2015)

Supplementation with 3 capsules of omega-3 (each containing $180 \mathrm{mg}$ EPA and $120 \mathrm{mg}$ DHA) daily for 2 months, resulted in a decrease in mean $\mathrm{LH}$ along with a significant change in LH/FSH ratio between groups in the omega-3 group, but no change in FSH (Nadjarzadeh et al 2015). In yet another study, no significant changes in concentrations of estrogen, LH, or FSH after fish oil capsule supplementation were reported (Phelan et al. 2011).

Obesity worsens PCOS. Research shows that in women with PCOS, fish oil supplementation at a dosage of $3.5 \mathrm{~g} /$ day for 6 weeks did not alter the body weight, BMI and Waist Circumference (WC) significantly, as compared to control group (Vargas et al, 2011). On the other hand, in a study conducted by Silva et al. (2013) BMI, WC and WHR were reduced after fish oil supplementation in women with type 2 diabetes. Khani et al (2017); Mohammadi et al (2012) and Hajianfer et al (2011) show that BMI in omega-3 fatty acid group was reduced significantly after intervention in comparison to the control group.

One gm of EPA/DHA daily in addition to consuming fish at least twice per week benefits Coronary heart disease patients, as per the recommendations of The American Heart Association (AHA), that also recommends taking a supplement of 2 to $4 \mathrm{gm}$ which may be beneficial in decreasing raised $\mathrm{Tg}$ levels. It has been reported that consumption of foods with anti-inflammatory 
properties improves androgenic profile (Liepa et al, 2008).

From the results of the present study it can be concluded that fish oil capsule supplementation exerts a favourable effect on the hormone profile of women with PCOS.

\section{References}

[1] Adams J, Polson DW, Franks S. Prevalence of polycystic ovaries in women with anovulation and idiopathic hirsutism. Br Med J (Clin Res Ed); 293:355-9, (1986).

[2] Alemzadeh R, Kichler J, Calhoun M. Spectrum of metabolic dysfunction in relationship with hyperandrogenemia in obese adolescent girls with polycystic ovary syndrome. Eur J Endocrinol ; 162:1093-9, (2010).

[3] Arslanian SA, Witchel SF. Polycystic ovary syndrome in adolescents: is there an epidemic? Current Opinion in Endocrinology. Curr Opin Endocrinol Diabetes Obes ; 9: 32-42, (2002).

[4] Azziz R, Woods KS, Reyna R, Key TJ, Knochenhauer ES and Yildiz BO. The prevalence and features of the polycystic ovary syndrome in an unselected population. $J$ Clin Endocrinol Metab; 89:2745-2749, (2004)

[5] Balen AH, Conway GS, Kaltsas G, Techatraisak K, Manning PJ, West C, Jacobs HS. Polycystic ovary syndrome: the spectrum of the disorder in 1741 patients. Hum Reprod ;10:2107-2111,(1995)

[6] Baptiste CG, Battista MC, Trottier A, Baillargeon JP. Insulin and hyperandrogenism in women with polycystic ovary syndrome. J Steroid Biochem Mol Biol ;122:42-52, (2010).

[7] Bart C. J. M. Fauser, Follicular development and oocyte maturation in hypogonadotrophic women employing recombinant folliclestimulating hormone: the role of oestradiol Human Reproduction Update; 3(2):101-108, (1997)

[8] Brannon, C. Essential Fatty Acids in Prevention and Treatment of Disease. Chapter 2 in Functional Foods Part 2. Continuing Education Course, Nutrition Dimension, Ashland, (2005).

[9] Bronstein J , Tawdekar S, Liu Y, Pawelczak M , David R, and B. Shah B, "Age of onset of polycystic ovarian syndrome in girls may be earlier than previously thought," Journal of Pediatric and Adolescent Gynecology, 2011; 24(1) :15-20, (2011)
[10]Christakou CD, Diamanti-Kandarakis E: Role of androgen excess on metabolic aberrations and cardiovascular risk in women with polycystic ovary syndrome. Womens Health (Lond Engl); 4:583-594,( 2008)

[11]Crosignani PG, Colombo M, Vegetti W, Somigliana E, Gessati A, Ragni G.Overweight and obese anovulatory patients with polycystic ovaries: parallel improvements in anthropometric indices, ovarian physiology and fertility rate induced by diet.;Hum Reprod.; 18(9):1928-32, (2003)

[12]Cussons AJ, Watts GF, Mori TA, Stuckey BGA. Omega-3fatty acid supplementation decreases liver fat content in polycystic ovary syndrome: A randomized controlled trial employing proton magnetic resonance spectroscopy. J Clin Endocrinol Metab.; 94;3842-8, (2009).

[13]Diamanti-Kandarakis $\mathrm{E}$ and Nadir $\mathrm{R} F$. Diagnosis and management of polycystic ovarian syndrome: Springer US; Chapter 2, The Menstrual Cycle in PCOS; Gill Sabrina and Janet E;15-22,(2009).

[14]Ebbesson SOE, Risica RM, Ebbesson LOE, Kennish JM, Tejero ME. Omega-3 fatty acids improve glucose tolerance and components of the metabolic syndrome in Alaskan eskimos: The Alaska Siberia project. Int J Circumpolar Health;64:396-408 (2005).

[15]Eid GM, Cottam DR, Velcu LM, Mattar S M, Korytkowski T M and Gosman G. Effective treatment of polycystic ovarian syndrome with Roux-en-Y gastric bypass. Surgery for Obesity and Related Diseases ; :77-80 (2005)

[16] Fakhoury H , Tamim H, Ferwana M, Siddiqui I A, Adham M and Tamimi W.Age and BMI Adjusted Comparison of Reproductive Hormones in PCOS.J Family Medici Prim Care 1(2):32-136, (2012)

[17]Forouhia N, Bidarb S S and Djafarian K. Effect of omega-3 fatty acids supplementation on testosterone levels in women with polycystic ovary syndrome: Meta-analysis of randomized controlled trials.J Nutr Sci \& Diet; 1(3): 165-70, (2015)

[18]Genie MA and Kalra S. Polycystic Ovary Syndrome -A metabolic malady, the mother of all lifestyle disorders in women - can Indian health budget tackle it in future? Ind $\mathrm{J}$ endocrino metabolism : 15(4); 239-41,(2011) .

[19] Glueck CJ, Papanna R, Wang P, Goldenberg $\mathrm{N}$, Sieve-Smith L. Incidence and treatment of metabolic syndrome in newly referred women with confirmed polycystic ovarian syndrome. Metabolism; 52:908-15, (2003).

[20] Goodarzi MO, Dumesic DA, Chazenbalk G, Azziz R. Polycystic ovary syndrome: etiology, 
pathogenesis and diagnosis. Nat Rev Endocrinol ; 7(4); 219-231, (2011).

[21] Hajianfar H, Hosseinzadeh MJ, Bahonar A, Mohammad K, Askari GR, Entezari MH, et al. The effect of omega-3 on the serum visfatin concentration in patients with type II diabetes. J Res Med Sci.;16:490-5, (2011)

[22] Hassa H, Tanir HM, Yildiz Z. Comparison of clinical and laboratory characteristics of cases with polycystic ovarian syndrome based on Rotterdam's criteria and women whose only clinical signs are oligo/anovulation or hirsutism. Arch Gynecol Obstet; 274:22732,(2006).

[23] Hoeger KM. Role of lifestyle modification in the management of polycystic ovary syndrome. Best Pract Res Clin Obstet Gynaecol ; 20:293310, (2006)

[24] Kauffman RP, Baker TE, Baker VM, Di Marino P, Castracane VD: Endocrine and metabolic differences among phenotypic expressions of polycystic ovary syndrome according to the 2003 Rotterdam consensus criteria. Am J Obstet Gynecol ; 198(670):671677, (2008).

[25] Kelly Chris C. J., Lyall Helen, John R. Petrie, Gould Gwyn W., Connell John M. C., Naveed Sattar, Low Grade Chronic Inflammation in Women with Polycystic Ovarian Syndrome. The Journal of Clinical Endocrinology \& Metabolism; 86(6); 2453-2455, (2013).

[26] Khani B, Mardanian F, and Fesharaki S J. Omega-3 supplementation effects on polycystic ovary syndrome symptoms and metabolic syndrome. J Res Med Sci.; 22: 64, (2017)

[27] Kratz M, Swarbrick MM, Callahan HS, Matthys CC, Havel PJ, Weigle DS. Effect of dietary $n-3$ polyunsaturated fatty acids on plasma total and high-molecular-weight adiponectin concentrations in overweight to moderately obese men and women. Am J Clin Nutr.; 87:347-53(2008)

[28]Liepa GU, Sengupta A, Karsies D. Polycystic ovary syndrome (PCOS) and other androgen excess-related conditions: can changes in dietary intake make a difference? Nutr Clin Pract.; 23(1): 63-71, (2008).

[29] Mehendale S. Oxidative stress-mediated essential poly unsaturated fatty acid alterations in female infertility. Hum fertile.2009;12:2833,(2009).

[30] Mohammadi E, Rafraf M, Farzadi L, AsghariJafarabadi M, Sabour S. Effects of omega-3 fatty acids supplementation on serum adiponectin levels and some metabolic risk factors in women with polycystic ovary syndrome. Asia Pac J Clin Nutr ;21:511-8, (2012).

[31] Moran L and Norman RJ. Understanding and managing disturbances in insulin metabolism and body weight in women with polycystic ovary syndrome. Best Practices and Research: Clinical Obstetrics and Gynaecology ;18 :719736 (2004) .

[32] Moran LJ, Noakes M, Clifton PM, Tomlinson L and Norman RJ. Dietary composition in restoring reproductive and metabolic physiology in overweight women with polycystic ovary syndrome. Journal of Clinical Endocrinology Metabolism ;88: 812-819, (2003).

[33] Nadjarzadeh A, Dehghani-Firouzabadi R, Daneshbodi H, Lotfi MH, Vaziri N, MozaffariKhosravi H. Effect of omega-3 supplementation on visfatin, adiponectin, and anthropometric indices in women with polycystic ovarian syndrome. J Reprod Infertil.; 16:212-20, (2015).

[34] Nadjarzadeh A, Firouzabadi R D. Vaziri N, Daneshbodi H, Lotfi $\mathrm{M} \mathrm{H}$ and Khosravi H M. The effect of omega-3 supplementation on androgen profile and menstrual status in women with polycystic ovary syndrome: A randomized clinical trial. Iranian Journal of Reproductive Medicine; 11(8): 665-672 (2013).

[35] National Institutes of Health: Evidence-based methodology workshop on polycystic ovary syndrome. Executive summary (2012)

[36] Navaratnarajah R, Pillay OC, Hardiman P: Polycystic ovary syndrome and endometrial cancer. Semin Reprod Med; 26:62-71, (2008)

[37] Nidhi R, Padmalha V, Nagarathna R., and Amritanshu R . Prevalence of Polycystic Ovarian Syndrome in Indian adolescent. Journal of Pediatrics and Adolescent Gynecology; 24(4) 223-227, (2011).

[38] Norman RJ, Davies MJ, Lord J and Moran LJ. The role of lifestyle modification in polycystic ovary syndrome. Trends in Endocrinology Metabolism ;13 :251-257, (2002).

[39] Oner G, Muderris II. Efficacy of omega-3 in the treatment of polycystic ovary syndrome. J Obstet Gynaecol;33:289-91, (2013)

[40]Pettigrew R and Hamilton-Fairley D. Obesity and female reproductive function. British Medical Bulletin; 53(2): 341-358,(1997).

[41] Phelan N, O’Connor A, Tun T K, Correia N, Boran G, Roche H M, and Gibney J. Hormonal and metabolic effects of polyunsaturated fatty acids in young women with polycystic ovary syndrome: results from a cross-sectional analysis and a randomized, placebo-controlled. Am J Clin Nutr ; 93:652-62,(2011). 
[42] Setji TL, Brown AJ. Polycystic ovary syndrome: Diagnosis and treatment. Am J Med; 120:128-32, (2007).

[43] Silva PS., Silva GMS , de Souza AP ; Effects of omega-3 polyunsaturated fatty acid supplementation in patients with chronic chagasic cardiomyopathy: study protocol for a randomized controlled trial. Trials ;14:379, (2013)

[44] Taher MA, Atia YA, Amin MK. Improving anovulation Rate in Women with Polycystic Ovary Syndrome by Using Silymarin. Global Journals Inc.; 12(6):16-21, (2012)
[45] Talbott EO, Zborowski JV, Rager JR, Boudreaux MY, Edmundowicz DA, Guzick DS: Evidence for an association between metabolic cardiovascular syndrome and coronary and aortic calcification among women with polycystic ovary syndrome. J Clin Endocrinol Metab; 89:5454-5461,(2004)

[46] Vargas ML, Almario RU, Buchan W, Kim K, Karakas SE. Metabolic and endocrine effects of long-chain versus essential omega-3 polyunsaturated fatty acids in polycystic ovary syndrome. Metabolism ;60:1711-8,(2011) 